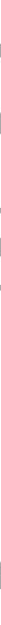




\section{ARQUEOLOGIA DE CONTRATO, COLONIALISMO INTERNO E POVOS INDÍGENAS NO BRASIL}

\section{JORGE EREMITES DE OLIVEIRA}

Universidade Federal de Pelotas, Pelotas/RS, BRASiL 


\title{
ARQUEOLOGIA DE CONTRATO, COLONIALISMO INTERNO E POVOS INDÍGENAS NO BRASIL
}

\section{Resumo}

No presente artigo, o autor analisa as relações entre Arqueologia de Contrato, colonialismo interno e povos indígenas no Brasil desde a década de 1990 até o tempo presente. A discussão está baseada em estudos desenvolvidos na região Centro-Oeste, especialmente no estado de Mato Grosso do Sul. Nesta parte do país ocorrem várias formas de violação dos direitos de povos originários, como a usurpação de territórios tradicionais. Em um contexto assim, a Arqueologia de Contrato tem sido utilizada para o licenciamento socioambiental de empreendimentos que afetam o território e a dinâmica da vida de muitas comunidades indígenas. Além disso, tem sido recorrida no Judiciário para a produção de estudos inconsistentes, do tipo junk science, em defesa dos interesses de setores que são contrários à regularização de territórios indígenas nesta parte da América do Sul.

Palavras-chave: Arqueologia do colonialismo; arqueologia de contrato no Brasil; direitos indígenas; colonialismo interno; povos indígenas no Brasil.

\section{CONTRACT ARCHAEOLOGY, INTERNAL COLONIALISM AND INDIGENOUS PEOPLES IN BRAZIL}

\begin{abstract}
This paper analyzes the relationship between Contract Archaeology, internal colonialism and indigenous peoples in Brazil from 1990s on. The discussion is based on studies that have been developed in the Centro-Oeste Region, especially in the State of Mato Grosso do Sul. In this region the rights of indigenous peoples have suffered from various forms of violation as is the case of the usurpation of their traditional territories. In such a context, CRM Archaeology has been used for environmental impact studies for large scale projects that have affected the territories and the ways of life of many indigenous communities. CRM Archaeology has been contested in the judicial system for the production of inconsistent reports, junk science style, because it has defended the interests of those contrary to the legalization of indigenous territories in this part of South America.

Keywords: Archaeology of colonialism; CRM archaeology in Brazil; indigenous rights; internal colonialism; indigenous peoples of Brazil.
\end{abstract}




\section{ARQUEOLOGÍA DE CONTRACTO, COLONIALISMO INTERNO Y PUEBLOS INDÍGENAS EN BRASIL}

\section{Resumen}

En este artículo, el autor analiza la relación entre la arqueología de contrato, el colonialismo interno y los pueblos indígenas en Brasil desde la década de 1990 hasta la actualidad. La discusión se basa en los estudios desarrollados en el Medio Oeste, especialmente en el estado de Mato Grosso do Sul. En esta parte del país producen se diversas formas de violación de los derechos de los pueblos indígenas, como la usurpación de territorios tradicionales. En este contexto, la Arqueología de Contrato se ha utilizado para el licenciamiento ambiental de los proyectos que afectan el territorio y la dinámica de la vida de muchas comunidades indígenas. Por otra parte, se ha impugnado en los tribunales para la producción de estudios inconsistentes, tipo ciencia basura, para defender los intereses de los sectores que son contrarios a la regularización de los territorios indígenas en esta parte de América del Sul.

Palabras-clave: Arqueologia del colonialismo; arqueología de contrato en Brasil; derechos indígenas; colonialismo interno; pueblos indígenas de Brasil.

Endereço do autor para correspondência: UFPel/ICH/Departamento de Antropologia e Arqueologia. Rua Alberto Rosa, 154 Centro - CEP 96.010-770 - Pelotas/RS, Brasil. 


\section{INTRODUÇÃO}

Neste trabalho apresento um conjunto de reflexões críticas a respeito das relações entre Arqueologia de Contrato, colonialismo interno e povos indígenas no Brasil. A discussão vai ao encontro de uma Antropologia e Arqueologia do Colonialismo, isto é, do estudo do colonialismo entendido de duas maneiras indissociáveis e complementares entre si: primeira, como sistema estruturante de relações sociais de poder, exploração e dominação que não está circunscrito a temporalidades do período colonial; segunda, como conjunto de problemas inerente à conformação, prática e produção de saberes nesses campos do conhecimento, originalmente constituídos no Ocidente (Himes 1972; Dirks 1995; Pels 1997, 2008; Cooper 2005; Lander 2005; Smith 2005; Atalay 2006; Moro Abadía 2006; Mignolo 2008; e outros). O colonialismo interno, por sua vez, é percebido como um sistema estruturante de igual natureza, porém particular a cada país e conectado a capilaridades transnacionais de um colonialismo global (González Casanova 1963, 1995, 2002 [1969], 2006; Cardoso de Oliveira 1978 [1966]; Pacheco de Oliveira 2006).

No caso da Arqueologia de Contrato, trata-se de uma modalidade da prática arqueológica que se apresenta como uma Arqueologia Empresarial, pois é produzida dentro de uma lógica empresarial e de mercado. Pressupõe a existência de complexas relações entre contratantes/ clientes/patrões e contratados/ negociantes/empregados. Em casos assim, o produto a ser vendido ou comercializado é o próprio trabalho do arqueólogo. Este produto é um laudo em seu sentido mais amplo, do latim laudare, quer dizer, um parecer técnicocientífico cuja elaboração pressupõe algum tipo de estudo ou pesquisa. Geralmente um serviço desse tipo está voltado para o licenciamento socioambiental de empreendimentos dos mais diversos, desde a revitalização de uma praça pública no Rio Grande do Sul até a construção de uma megausina hidrelétrica no Pará. Contudo, por meio do contrato também é possível produzir outros tantos tipos de trabalhos. Exemplo disso são os laudos administrativos e periciais, produzidos na esfera governamental e para o Judiciário, respectivamente, sobre áreas reivindicadas por povos indígenas e outras comunidades tradicionais, como as remanescentes dos quilombos ${ }^{1}$. Em situações desse tipo, por vezes tem sido constatada a elaboração de trabalhos chamados de contralaudos, encomendados para defender sujeitos e organizações ligadas ao movimento ruralista, os quais se apresentam como contratantes e partes envolvidas em litígios judiciais pela posse de terras no Brasil $^{2}$.

Para tratar de um assunto demasiado complexo, valho-me basicamente de observações realizadas entre 2003 e 2012 na região Centro-Oeste, período em que participei, ora como arqueólogo, ora como antropólogo social, de dois tipos de trabalhos. O primeiro diz respeito à produção de um laudo administrativo e dois laudos periciais ou judiciais sobre terras indígenas (Eremites de Oliveira \& Pereira 2009a [2007], 
2012 [2003]; Eremites de Oliveira et al. 2011b). O segundo tem a ver com a realização de estudos complementares a relatórios sobre impactos socioambientais de empreendimentos que afetam comunidades indígenas: duas rodovias, uma linha de transmissão de energia e uma mineradora de ouro (Eremites de Oliveira 2010 [2008]; Eremites de Oliveira \& Pereira 2009b, 2011; Eremites de Oliveira et al. 2011a). Acrescenta-se ainda informações obtidas em 2013, 2014 e 2015 a partir da interlocução mantida sobre o tema com estudantes de Arqueologia e colegas que atuam em universidades, museus, órgãos do Estado, empresas e outras instituições que de alguma forma estão ligadas à Arqueologia de Contrato.

A intenção aqui não é reduzir a discussão a um binarismo do tipo "os que são a favor" versus "os que são contra" a Arqueologia de Contrato. Fazer isso seria desconsiderar o que Rocha et al. (2013: 132) apropriadamente chamam de "dicotomização reducionista que cria uma oposição entre pesquisadores 'ingênuos e idealistas' e pesquisadores 'ambiciosos que venderam as almas ao capital"'. A proposição defendida é outra: estímulo à manutenção de uma postura crítica sobre esta e outras modalidades da prática arqueológica no Brasil e em outros países.

\section{DO COLONIALISMO INTERNO A OUTROS ASSUNTOS CORRELATOS}

As origens do colonialismo interno remontam ao processo de independência de ex-colônias europeias e à constituição dos estados-nações (Estados modernos) nas Américas e em outros continentes. Foi nesse momento que as elites criollas ascenderam ao poder central e passaram a ter controle sobre o aparato estatal, conforme explicado por González Casanova (2006). No caso americano, tais elites geralmente descendem de europeus e não se identificam com as populações indígenas. Portanto, quando surgiram novos estados-nações nesta parte do globo, a partir da segunda metade do século XVIII, os mesmos não foram constituídos em atenção aos direitos dos coletivos originários que estavam aqui antes da existência de países como Argentina, Brasil, Cuba, México e Estados Unidos.

A referida categoria analítica foi inicialmente difundida na Antropologia Brasileira nos anos 1960 por Cardoso de Oliveira (1978 [1966]), cujas ideias tiveram inspiração nos aportes de $\mathrm{Ba}$ landier (1993 [1951]), González Casanova (1963) e outros autores. Serviu de base para o antropólogo formular a teoria da fricção interétnica, uma ruptura com a abordagem culturalista e com o paradigma da aculturação que influenciavam os estudos etnológicos.

Naquele tempo, apenas para exemplificar, grande parte da Arqueologia Brasileira estava marcada pela influência histórico-cultural do PRONAPA (Programa Nacional de Pesquisas Arqueológicas), desenvolvido no período de 1965 a 1970, sob a coordenação do casal Betty J. Meggers e Clifford Evans (Souza 1991; Prous 1992; Dias 1995). Em que pese não desconhecer ou desprezar as valiosas contribuições do programa, pelo contrário, o fato é que 
à época a abordagem histórico-cultural era bastante criticada na Arqueologia Americana. As críticas mais conhecidas vieram do movimento da Nova Arqueologia ou Arqueologia Processual, cujas influências mais significativas chegaram muito tardiamente ao Brasil, basicamente a partir dos anos 1980. Para o período também é apontada a constituição de um establishment que passou a controlar e influenciar a Arqueologia em várias regiões, cujas articulações vão para além do referido programa, mantendo a disciplina pouco aberta à inovação ou renovação $(\mathrm{Fu}-$ nari 1989, 1994; Dias 1995; Eremites de Oliveira 2002). A partir de então, e por razões das mais complexas, a Antropologia Social e a Arqueologia seguiram caminhos distintos em muitas instituições brasileiras: a primeira mais ligada à Sociologia e à Ciência Política, resultado de uma antiga aliança nas $\mathrm{Ci}$ ências Sociais; e a segunda mais próxima da História.

Anos mais tarde, nas décadas de 1990 e 2000, em tempos também marcados pelo pluralismo teórico-metodológico da Arqueologia Pós-Processual e a renovação da disciplina em nível mundial, teve início uma (re) aproximação entre os dois campos do conhecimento. As transformações tiveram reflexos positivos na posterior abertura de novos cursos de graduação e programas de pós-graduação em que a Antropologia Social e a Arqueologia passaram a estar juntas e articuladas, como ocorre, por exemplo, na Universidade Federal de Minas Gerais, Universidade Federal do Pará e Universidade Federal de Pelotas. Sobre o assunto, cumpre registrar que apenas no Pará esta articulação abrange a Bioantropologia e esforços têm sido mantidos para que seja estendida à Linguística Antropológica (Eremites de Oliveira 2014).

A questão a destacar é que muitas das perspectivas epistêmicas adotadas desde longa data na Antropologia Brasileira estão ligadas ao que alguns chamam, de um ponto de vista sociológico, de nation-building ou projeto de "construção da nação". Trata-se da tradição de haver compromisso dos antropólogos sociais em relação aos grupos com os quais trabalham, algo também percebido como ativismo político voltado para a garantia de direitos (Peirano 2000; Cabral 2004; O’Dwyer 2015). Postura diferente foi adotada na Arqueologia, conhecida pela violência epistêmica construída em relação aos povos indígenas, característica esta que não é exclusiva da disciplina no país (Gnecco \& Langeback 2006; Gnecco 2009). Portanto, na origem de sua institucionalização, a Arqueologia Brasileira estaria mais voltada para um projeto de "construção do Estado" (State-building) do que para um projeto de "construção da nação” (nation-building).

A diferença apontada explica, ao menos em parte, a ruptura e o distanciamento epistemológico verificado entre a chamada Arqueologia Pré-histórica em relação à Etnologia Indígena e à Etno-história. Por este e outros motivos ainda há relativamente poucos estudos voltados à Etnoarqueologia, Arqueologia Indígena, Arqueologia Colaborativa e Arqueologia Pública nesta parte da América do Sul. Todavia, avanços têm sido crescentes e re- 
gistrados aqui, ali e acolá nas últimas décadas, como atestam os trabalhos de Silva et al. (2008, 2011), Stuchi (2010), Bezerra (2011), Moraes (2012), Wanderley (2013) e outros.

Exemplo dessa situação pode ser constatado na seguinte avaliação, feita em fins dos anos 1990 e, portanto, datada, sobre a história da Arqueologia praticada no Brasil:

"A maior parte do conhecimento arqueológico produzido no Brasil trata do período pré-cabralino. A arqueologia feita no Brasil é essencialmente uma arqueologia de sociedades indígenas extintas que viveram em um passado distante, deixando como testemunho de sua existência somente restos materiais" (Barreto, 1999/2000: 33). [destaques meus]

A ideia destacada remete a uma postura epistêmica vinculada à existência de uma ruptura temporal entre a pré-história (tempo sem escrita) e a história (tempo com escrita), como se os povos indígenas atuais nada tivessem a ver com aqueles do passado pré-colonial. Também chama à atenção para a incorporação e o uso acrítico do termo pré-história, cunhado em 1851 por Daniel Wilson, sob forte influência do evolucionismo e do Iluminismo (Trigger 2004). Trata-se, portanto, de uma categoria evolucionista naturalizada e institucionalizada na Arqueologia Mundial, inclusive no âmbito de uma perspectiva historiográfica que circunscreve os povos ameríndios a temporalidades pré-coloniais (Eremites de Oliveira 2012). Nesta linha de raciocínio, o lugar-comum do Outro é representado como distante do tempo presente, isto é, da civilização, e relegado ao tempo dos selvagens primitivos (ver Fabian 2013). Soma-se a isso a influência do paradigma da aculturação que também marca as estruturas de pensamento, o estabelecimento do objeto de estudo e a produção intelectual de muitos arqueólogos.

Com efeito, a noção de colonialismo interno torna-se relevante para analisar o papel de profissionais e empresas ligadas à Arqueologia de Contrato em cenários marcados pela violação dos direitos de povos indígenas. Este é o caso de situações históricas caracterizadas pelo avanço das frentes de expansão e implantação de projetos desenvolvimentistas no Brasil. Um sistema estruturante assim é caracterizado por relações sociais e de poder, leis, práticas, burocracias e saberes que caracterizam formas de exploração, dominação e manutenção de assimetrias por parte das elites nacionais contra coletivos étnica e culturalmente distintos em relação a si ou à maioria da população. Este é caso da percepção de que o patrimônio arqueológico, sobretudo o referente ao passado indígena pré-colonial, seria algo meramente estatal e, portanto, protegido por lei e não pertencente aos povos originários no tempo presente (Ferreira 2013).

Esta situação tem sido verificada com relação a comunidades Guarani e Kaiowá confinadas em pequenas reservas indígenas ou expulsas de suas terras em Mato Grosso do Sul, muitas delas acampadas às margens de rodovias que cortam o estado (Brand 1997; Cavalcante 2013). Em casos assim, coleti- 
vidades inteiras permanecem sitiadas e constrangidas por diversos mecanismos de sujeição: tolhimento da liberdade de ir e vir em seus próprios territórios; ameaças de morte e assassinato de lideranças; imposição do português como língua oficial para se comunicar com autoridades e órgãos do Estado; intolerância de missões evangélicas que demonizam as religiões nativas e promovem outras formas de violência; implantação de uma política de educação formal e assistência à saúde em desatenção às particularidades de cada comunidade; ação de setores da imprensa na construção de uma imagem negativa sobre os índios; destruição de sítios arqueológicos mais recentes, como cemitérios e antigos assentamentos dos séculos XIX e XX; etc.

Mecanismos de sujeição também são impostos a povos indígenas e comunidades locais de todo tipo quando da implantação de projetos desenvolvimentistas, como a Usina Hidrelétrica de Belo Monte, maior obra do PAC (Programa de Aceleração do Crescimento). Neste caso emblemático, as comunidades não foram prévia e devidamente consultadas para o licenciamento do empreendimento, o que configura violação de direitos assegurados na Constituição Federal de 1988 e na Convenção no .169 da OIT (Organização Internacional do Trabalho).

Uma questão polêmica sobre o assunto reside no fato do licenciamento desses projetos também contar com o trabalho de arqueólogos e outros profissionais. Isso geralmente ocorre de maneira acrítica e em um contexto histórico mais amplo, marcado pela mundializa- ção do capital (Chesnais 1996). Neste cenário há, concomitantemente, a descentralização de operações produtivas e a centralização do capital, haja vista sua necessidade de acumulação. Disso resulta a re-localização de investimentos e atividades produtivas, o que gera a polarização da riqueza a favor de potências situadas no hemisfério Norte. Para países localizados no hemisfério Sul, por outro lado, há a transferência de menos riquezas e o registro de múltiplos impactos negativos. Na parte meridional do planeta estão países com jovens democracias, economias em crescimento e uma história marcada por ditaduras, grandes esquemas de corrupção nos poderes institucionais e políticas colonialistas. No Brasil e em outros países latino-americanos, portanto, existem classes sociais, povos originários e minorias étnicas em situação de vulnerabilidade social (Zhouri \& Oliveira 2007; Roberto de Paula 2010). Esses coletivos são os que mais sofrem com isso tudo, principalmente quando expulsos de suas terras em nome do progresso e da civilização.

\section{DA ARQUEOLOGIA DE CONTRATO À ARQUEOLOGIA PELAS GENTES}

O termo Arqueologia de Contrato foi popularizado no Brasil a partir da década de 1990. Tal como aconteceu no âmbito da Arqueologia Mundial, a ideia inicial era distinguir a nova modalidade de trabalho em relação à Arqueologia praticada em universidades, museus e outras instituições. Desenvolveu-se em um contexto histórico marcado pelo processo de (re) democratização, re- 
tomada do crescimento econômico e posterior expansão do ensino superior. A situação é mais bem verificada após o fim do regime militar (1964-1985) e posteriormente à promulgação da Constituição Federal de 1988. No período também passou a vigorar uma nova legislação para o licenciamento de empreendimentos potencialmente degradantes para o meio ambiente e os seres humanos, incluindo o patrimônio cultural.

Todas essas mudanças favoreceram ao crescimento da Arqueologia de Contrato, especialmente para o licenciamento socioambiental, e estimularam as primeiras discussões nacionais sobre o tema (ver, p. ex., Caldarelli 1997; Caldarelli \& Santos 2000; SAB 2002).

Desde então, a Arqueologia de Contrato cresceu vertiginosamente e na década de 2000 passou a responder por mais de $95 \%$ das pesquisas realizadas no país com autorização do IPHAN - Instituto do Patrimônio Histórico e Artístico Nacional (Zanettini 2009; Wichers 2010; Ferreira 2013). Esses números, contudo, não possuem a mesma proporcionalidade no que diz respeito a publicações científicas. Ocorre que a produção intelectual de maior impacto científico ainda é feita, paradoxalmente, por arqueólogos que mais atuam como docentes e pesquisadores em universidades e museus do que como técnicos ou empresários ligados exclusivamente ao contrato.

Por tudo isso e muito mais, o termo Arqueologia de Contrato às vezes possui conotação pejorativa, como se fosse algo menor, motivo pelo qual alguns preferem chamá-la de Arqueologia Consultiva ou Arqueologia Preventiva, ao invés de designá-la como Arqueologia Empresarial. Também é praticamente desconhecida e ignorada a produção e comercialização de contralaudos e pareceres, inclusive os do tipo junk science ${ }^{4}$, usados no âmbito do Judiciário para defender pessoas e organizações contrárias à regularização das terras indígenas e quilombolas no país (ver Almeida 2015).

Consequentemente, se no começo a Arqueologia de Contrato foi recebida com certo entusiasmo, posteriormente passou a ser vista com decepção por muitos de nós. Há, inclusive, os que avaliam que estamos diante de uma verdadeira tragédia na Arqueologia Brasileira, segundo pontuou Cristóbal Gnecco em conferência proferida na cidade de Florianópolis, Santa Catarina, em 2012. Avaliação semelhante e mais detalhada foi feita em 2013 no documento Arqueologia pelas gentes, assinado por cinco arqueólogos brasileiros (Rocha et al. 2013).

Os autores do citado manifesto argumentam sobre dez questões básicas referentes à Arqueologia de Contrato no Brasil. Primeira, que a trajetória atual da Arqueologia Brasileira destoa da agenda da Arqueologia Mundial promovida pelo WAC (Word Archaeological Congress), especialmente no que se refere à mediação de interesses entre comunidades locais, instituições públicas e empresas estatais e privadas. Segunda, que o governo brasileiro assume uma postura autoritária e desenvolvimentista em relação aos povos indígenas em todo o país, sistematicamente violando 
seus direitos. Terceira, que a maioria da comunidade arqueológica é omissa e conivente diante da falta de conduta ética por parte de arqueólogos e empresas ligados ao contrato, como ocorre nos casos de violação de direitos dos povos indígenas e comunidades tradicionais afetados por projetos desenvolvimentistas. Quarta, que muitos arqueólogos são cúmplices de processos ilegais de expropriação e espoliação de territórios tradicionais, bens culturais e recursos naturais. Quinta, que os arqueólogos devem contribuir para a promoção e valorização da diversidade sociocultural, inclusive rompendo com a violência epistêmica observada em museus onde os povos indígenas aparecem fossilizados e relegados a um passado distante dos dias atuais. Sexta, que a Arqueologia quando feita por meio do contrato não deve ser resumida a conhecimentos desconexos, não reflexivos e produzidos em prazos exíguos e sem a inclusão das comunidades e instituições afetadas pelos empreendimentos. Sétima, que mesmo os arqueólogos que atuam no sentido contrário às críticas apresentadas, geralmente têm seus direitos autorais violados e os dados de suas pesquisas manipulados para atender aos interesses de contratantes e empreendedores. Oitava, que tem sido recorrente a violação do patrimônio cultural de comunidades indígenas, como aconteceu com os Munduruku afetados por projetos hidrelétricos na região amazônica. Nona, que à época da divulgação do manifesto, o Código de Ética da SAB estava obsoleto - e ilegal - no que se refere à relação dos arqueólogos com povos e comunidades tradicionais, condicionando o reconhecimento de seus direitos sobre o patrimônio cultural à comprovação de sua vinculação ancestral com o mesmo 5 . Décima, que a Arqueologia Brasileira está "sendo dominada por 'buracólogos' acríticos e autômatos" (Rocha et al. 2013: 133), o que sugere a existência de um novo establishment na Arqueologia nacional, vinculado ao contrato. Esta é, em minha opinião, a mais contundente, corajosa e dura crítica à Arqueologia de Contrato e à Arqueologia Brasileira elaborada nas últimas décadas.

\section{DA AVALIAÇÃo GERAL À ANÁlISE DE UM CASO}

Em fins dos anos 1980 e meados dos 1990, quando a Arqueologia de Contrato ainda era incipiente no Brasil, muitos jovens arqueólogos aspiravam seguir a carreira de seus mestres e atuar como pesquisadores e professores em universidades e museus. Este foi o momento em que a Arqueologia Empresarial surgiu, cresceu e construiu um know-how voltado para a negociação, elaboração e desenvolvimento de projetos, incluindo orçamentos, prazos, serviços e produtos. Também registrou avanços no que se refere, por exemplo, à aplicação de técnicas e métodos para o levantamento arqueológico, além de produzir conhecimento sobre áreas pouco estudadas e favorecer a geração de novos postos de trabalho. Constituiuse, ainda, como oportunidade para alguns colegas continuarem na 
profissão de arqueólogo e poderem trabalhar para além das relações de poder estabelecidas em certas instituições.

Atualmente, porém, não é raro observar profissionais recémformados em Arqueologia ou em campos afins, estudantes de graduação e até pseudo-arqueólogos a trabalhar sozinhos em campo, sem a necessária supervisão de um profissional mais experiente. Chegam a ganhar por produtividade e têm metas a cumprir, como em um sistema taylorista ou fordista de trabalho fabril: quantidade de sondagens a fazer, distâncias a percorrer em quilômetros, número de quadrículas a escavar, relatórios a escrever e encaminhar etc. Situações assim favorecem a existência de certa assimetria de gênero na Arqueologia Brasileira, especialmente nos casos em que os homens ganham mais que as mulheres para a realização de trabalhos de campo que demandam maior força física.

Às vezes profissionais recém-formados são contratados por seus próprios professores-empregadores, os quais realizam trabalhos de contrato através das fundações ligadas às universidades ou por meio de empresas particulares. Há ainda casos em que são contatados a trabalhar por meio das redes sociais, como Facebook, Linkedin e Whatsapp. Desde cedo passam por um processo de alienação frente à lógica do capital, à mais-valia e, consequentemente, à própria terceirização precária do trabalho (observada, por exemplo, na contratação de arqueólogos que atuam como autônomos ou freelancers). Geralmente minimizam a responsabilidade social do ofício de arqueólogo, reduzindo-o a uma mera técnica, como se o campo fizesse o profissional. Mais ainda, frequentemente reproduzem discursos voltados para a excelência técnico-científica de seus trabalhos, postura esta que corrobora a tese do desenvolvimento a qualquer custo, diretriz das ações do governo brasileiro desde a década de 1990, quando houve a retomada do crescimento econômico. Soma-se a isso a ingênua ideia de neutralidade científica, especialmente quando se trata do licenciamento de projetos que afetam a dinâmica da vida em sociedade e a reprodução física e cultural de povos e comunidades tradicionais.

Sabe-se, no entanto, que há pessoas e empresas que buscam atuar com seriedade no contrato, embora encontrem grandes dificuldades no relacionamento com empreendedores, muitos dos quais apenas desejam se livrar do "problema" atribuído à Arqueologia. A situação é agravada quando arqueólogos são chamados às pressas para realizar serviços que deveriam ter sido concluídos anteriormente, e têm seus direitos autorais violados.

Neste sentido, tenho observado dois grandes problemas relacionados à Arqueologia de Contrato e seu uso para o licenciamento de empreendimentos que afetam os povos originários, cuja crítica pode ser extensiva a outros contextos similares.

O primeiro problema diz respeito à existência de arqueólogos que realizam estudos sem qualquer interlocução simétrica com as comunidades indígenas 
(caciques, xamãs, agentes de saúde, professores, mulheres, crianças etc.). A situação torna-se gravíssima quando os trabalhos são executados dentro ou no entorno de terras indígenas ainda não regularizadas pelo Estado Brasileiro. Trata-se de um problema verificado na área de ampliação da Terra Indígena Buriti, em Mato Grosso do Sul, afetada por uma linha de transmissão de energia, e na área de ocupação tradicional do Santuário dos Pajés, em Brasília, atingida por um empreendimento imobiliário. Em lugares assim, paisagens humanizadas e sítios arqueológicos mais recentes são deliberadamente desconsiderados, haja vista que os arqueólogos são os profissionais com autoridade para dizer o que é e o que não é sítio arqueológico. Por isso chegam a profanar lugares sagrados e outros locais com significado tradicional, perturbando diretamente a dinâmica da vida em sociedade. Situação análoga ocorre com a educação patrimonial, usualmente confundida com Arqueologia Pública, reduzida a levar conhecimentos ao Outro por meio da realização de oficinas, palestras e distribuição de cartilhas.

O segundo problema diz respeito ao fato de arqueólogos tornam-se agentes do colonialismo interno quando trabalham, pois, acriticamente no licenciamento de projetos desenvolvimentistas. Isso ocorre à medida que seus trabalhos também servem para ceifar direitos étnicos, sobretudo direitos territoriais. Exemplo disso ocorre quando o resultado de um laudo arqueológico, produzido para o licenciamento socioambiental, é usado no Judiciário para corroborar a tese de que determinada área não seria terra indígena, haja vista que ali não teriam sido encontradas provas materiais (objetos) de ocupação tradicional. Se uma situação desse tipo é considerada preocupante, embora desconsiderada pela maioria dos arqueólogos que atuam no contrato, a produção de contralaudos do tipo junk science é simplesmente inadmissível.

Relativo a este assunto, em particular, faz-se necessário analisar a questão dos contralaudos produzidos no âmbito da Arqueologia de Contrato. Para este propósito, valho-me aqui das experiências que tive por conta da participação na elaboração do laudo pericial de natureza antropológica, arqueológica e histórica sobre a Terra Indígena Buriti (Eremites de Oliveira \& Pereira 2012). O estudo foi realizado por meio da parceria com um antropólogo social, desenvolvido em um período de três meses e entregue à Justiça Federal de Campo Grande, Mato Grosso do Sul, em fins de 2003. Originalmente possui 334 páginas e 10 documentos anexos: partes do diário de campo de Roberto Cardoso de Oliveira (2002), que esteve em Buriti no começo dos anos 1950; documentos da década de 1940, produzidos por funcionários da agência indigenista oficial; e outros. No trabalho também constam dados sistematicamente obtidos e analisados através de pesquisa etnoarqueológica, etnográfica e etno-histórica, os quais comprovam que a área periciada é, de fato, terra indígena ${ }^{6}$.

O referido laudo pericial foi objeto de críticas apresentadas em um parecer sob forma de contralaudo no começo 
de 2004, cujo trabalho contém 16 páginas (Martins 2004). Trata-se de um parecer repleto de inconsistências e impropriedades, espécie de junk science, cujo propósito maior é construir a "verdade" que interessa aos contratantes. Foi produzido por um arqueólogo que à época sequer foi à região de Buriti realizar algum estudo arqueológico, etnológico ou etno-histórico para embasar seu trabalho com dados empíricos. Valeu-se basicamente do serviço de terceiros que não eram arqueólogos ou antropólogos sociais, da autoridade científica e do poder que tinha para autorizar a própria fala e defender ruralistas envolvidos no litígio. $\mathrm{O}$ trabalho teria sido "uma consultoria técnico-científica, neutra, avaliativa do laudo pericial em epígrafe" (Martins 2004: 3752), como se houvesse neutralidade científica em Arqueologia ou em outra disciplina.

O citado parecer evidencia uma estratégia bastante conhecida entre antropólogos sociais que realizam este tipo de perícia no Brasil. Inicialmente o autor desqualifica profissionalmente e acusa de intolerante e parcial o arqueólogo perito da Justiça Federal. O problema maior reside no fato de que isso também foi feito com a autoridade de ser "presidente nacional da SAB - Sociedade de Arqueologia Brasileira" (Martins 2004: 3752). No texto elaborado consta um desprezo à pesquisa etnográfica, etnoarqueológica e etnohistórica contida no laudo judicial. A autoria do trabalho entende que deveria ter havido "escavações sistemáticas (sem o que não há prática arqueológica)", especialmente para compreender o processo de ocupação humana da região desde tempos précoloniais (Martins 2004: 3753). Ao fazer isso, menospreza o subcampo da Etnoarqueologia e, por conseguinte, sua contribuição à Arqueologia e à produção de laudos antropológicos sobre terras indígenas, diferentemente do que tenho defendido amiúde (ver, p. ex., Eremites de Oliveira 2012, 2015). Chega a fazer referência a uma publicação de sua autoria, também resultado de um trabalho de contrato, cujo assunto não tem relação direta com a presença dos Terena na Serra de Maracaju, mas à "pré-história" da região. Além disso, interpreta de maneira equivocada a legislação indigenista sobre o tema, deturpando o conceito de terras indígenas como se fossem áreas ocupadas ininterruptamente desde tempos précoloniais até o tempo presente, como de costume fez em outra ocasião (ver Eremites de Oliveira 2007). Além disso, assevera seus argumentos desqualificando o arqueólogo perito:

"É rigorosamente inaceitável, no estudo apresentado pelo perito, que, além de sua produção científica, voltada exclusivamente para a realidade dos índios Guató, cujo contexto pretérito é totalmente distinto dos Terena e da realidade arqueológica da região da área em litígio, o mesmo não tenha recorrido à bibliografia arqueológica regional, publicada na última década, sobretudo àquela existente sobre as proximidades da área em litígio". (Martins 2004: 3755) [destaques meus] 
Depois disso, argumenta, dentre outras coisas, que a área em litígio teria sido ocupada concomitantemente por indígenas e fazendeiros que se estabeleceram naquela região serrana após o término da guerra entre o Paraguai e a Tríplice Aliança (1864-1870). Ao fazer isso, omite-se de discutir o fato dos peritos terem constatado, inclusive por meio da memória social e de genealogias, que os Terena estavam ali desde, ao menos, a década de 1850. Também deixa de aprofundar o debate sobre a expulsão de famílias indígenas da área em litígio, a qual havia sido identificada e delimitada pela FUNAI (Fundação Nacional do Índio) como terra tradicionalmente ocupada.

Uma situação desse tipo seria percebida como desvio de conduta ética e teria grande repercussão em várias categorias profissionais e associações científicas. No entanto, à época foi tratada como algo de menor importância por alguns colegas associados da $\mathrm{SAB}$ que tomaram ciência dos fatos. Este tipo de postura atesta, dentre outras coisas, a violência epistêmica e o distanciamento da Arqueologia Brasileira em relação à realidade dos povos indígenas no tempo presente.

\section{CONCLUSÃO}

A Arqueologia de Contrato é uma modalidade relativamente recente no âmbito da história da disciplina em nível mundial. Seu vertiginoso crescimento no Brasil resulta, sobretudo, de uma demanda crescente do mercado pelo trabalho do arqueólogo para a elaboração de estudos inter e multidiscipli- nares para o licenciamento de empreendimentos dos mais diversos. Esta situação é verificada após a década perdida de 1980, quando a economia da América Latina registrou significativa estagnação. Com efeito, o crescimento registrado nos anos 1990 trouxe consigo outras demandas no que se refere à formação de novos profissionais. Em resposta a esta situação, dentre outras justificativas, cursos de graduação e programas de pós-graduação foram abertos em muitas regiões do país. Por outro lado, problemas então inexistentes ou pouco conhecidos e debatidos passaram a chamar à atenção e estimulam a reflexão crítica sobre o assunto. Este é o caso da complexa relação existente entre Arqueologia Empresarial, colonialismo interno e povos indígenas no Brasil.

Neste sentido, a Arqueologia de Contrato quando praticada dentro ou nas proximidades de terras indígenas, estejam ou não regularizadas pelo Estado Brasileiro, precisa ser realizada de forma participativa e simétrica a envolver as comunidades afetadas. Esta observação remete à incorporação de saberes indígenas na interpretação do registro arqueológico, incluindo paisagens humanizadas e evidências materiais sobre a ocupação recente. Trabalhos assim também necessitam ser acompanhados pelas comunidades, entidades da sociedade civil e órgãos públicos (Ministério Público Federal, FUNAI, IPHAN etc.). No caso de relatórios produzidos para o licenciamento de projetos desenvolvimentistas, entendo ainda que os estudos devam ser previamente apresentados, discutidos e 
formalmente aprovados pelas comunidades, em atenção à Convenção $\mathrm{n}^{\circ}$. 169 da OIT e a dispositivos constantes na legislação nacional. Proceder dessa forma implica em superar a violência epistêmica e certas práticas colonialistas que marcam a história da Arqueologia Brasileira. No caso específico de contralaudos, configurados ou não como trabalhos do tipo junk science, faz-se imprescindível que as associações possam apurar as denúncias sobre eventuais desvios de conduta que cheguem ao seu conhecimento. Isso deve ser feito de modo a garantir o amplo direito de defesa e como forma de nortear condutas éticas relativas aos direitos e compromissos dos profissionais de Arqueologia.

No caso dos povos indígenas contemporâneos, cujos antepassados estavam aqui muito antes dos primeiros conquistadores europeus cruzarem o Atlântico, os mesmos ainda são quase que desconhecidos pelos arqueólogos brasileiros. Sobre eles foram construídas representações estereotipadas, não raramente norteadas pela ideia de aculturação ou perdas culturais, produto do evolucionismo e do Iluminismo do século XVIII. Chega-se a falar sobre um provável fim da Etnoarqueologia, devido ao fato de haver poucos coletivos que ainda produzam vasilhas cerâmicas e artefatos líticos e possuam uma economia baseada na caça e coleta. Uma perspectiva desse tipo revela que muitos arqueólogos têm mais interesse pelos objetos do que pelos seres humanos. Além disso, sobre os antepassados pré-coloniais dos povos originários, por outro lado, construímos um con- junto de representações de igual natureza. Não raramente são reducionistas, fossilizadas, exóticas e essencialistas, pensadas a partir de teorias importadas de outras latitudes, sem base etnográfica na América do Sul. Na verdade, por décadas desprezamos a observação participante, a Etnologia Indígena e a Etno-história em nome de tipologias, classificações e estatísticas sobre a cultura material. Negamo-nos deliberadamente a ter um encontro vis-à-vis com o Outro, por vezes relegado à posição de subalternidade e, consequentemente, sem direito à voz, história, território e modo de vida diferenciado. Logo, nada teria a contribuir com a disciplina arqueológica. Ledo engano!

Apesar da crítica apresentada, entendo que o conhecimento produzido pelos arqueólogos pode, sim, provocar mudanças positivas para a construção de outro projeto de nação, haja vista três questionamentos filosóficos básicos: Quem somos? De onde viemos? Para onde vamos? Quanto a isso, registro meu ceticismo no que se refere à incorporação de saberes produzidos no subcampo da Arqueologia Pré-histórica à história nacional. Ocorre que se tais conhecimentos não servirem para dar consistência, visibilidade e valorização a uma história indígena total e de longa duração, assim percebida em termos espaciais e temporais, tudo o mais ficará restrito ao essencialismo e ao exotismo da academia e dos museus.

Diante do exposto, defendo a ideia de seguirmos com uma postura crítica frente à Arqueologia de Contrato e à Arqueologia em geral. Esta atitude remete à necessidade de haver um con- 
tínuo (re) pensar sobre a formação e a práxis dos arqueólogos. Requer ainda a necessária desobediência epistêmica, espécie de indisciplina libertária e insurgente, imprescindível para o processo de descolonização da disciplina no Brasil.

\section{NOTAS}

${ }^{1}$ No Brasil, o termo quilombola normalmente é usado para se referir a sujeitos e comunidades de origem afroamericana e, portanto, com um passado ligado à escravidão de negros trazidos da África para a América do Sul, cujos coletivos geralmente possuem uma organização social da cultura diferenciada em relação à sociedade nacional. São juridicamente reconhecidos como "comunidades remanescentes dos quilombos”, em observação ao Art. 68 do Ato das Disposições Constitucionais Transitórias da Constituição Federal de 1988, o que tem a ver com autoidentificação.

2 Laudos judiciais são estudos técnico-científicos feitos por profissionais designados como peritos pela Justiça, os quais possuem expertise sobre assuntos ligados a questões litigiosas, como, por exemplo, a posse de determinada terra ou outro tema. Contralaudos, por sua vez, são estudos feitos por assistentes técnicos, ou seja, expertos contratados para defender pessoas ou instituições que são partes em processos judiciais a envolver direitos.

${ }^{3}$ Outros pesquisadores estrangeiros e brasileiros também contribuíram para o desenvolvimento da Arqueologia Brasileira, como, por exemplo, o casal francês Joseph Emperaire e Annette Laming-Emperaire, o estadunidense Wesley R. Hurt Jr. e os brasileiros Luiz de Castro Faria, José Loureiro Fernandes e Paulo Duarte, dentre outros.

${ }^{4}$ A expressão junk science é usada nos Esta- dos Unidos para indicar qualquer produção científica considerada de menor valor, às vezes espúria ou fraudulenta, apresentada em processos para influenciar decisões judiciais.

${ }^{5}$ No dia $1^{\circ} / 10 / 2015$, durante o XVIII Congresso da $\mathrm{SAB}$, um dos mais profícuos eventos promovidos pela associação, realizado na cidade de Goiânia, nas dependências da Pontifícia Universidade Católica de Goiás (PUC Goiás), foi aprovado em assembleia o novo código de ética da Sociedade de Arqueologia Brasileira, no qual esta e outras questões foram tratadas à altura dos novos desafios enfrentados no país.

${ }^{6}$ Vale registrar que a Constituição Federal de 1988, em seu Art. 231, assim define o que são terras indígenas no Brasil: "s $1^{\circ}$ São terras tradicionalmente ocupadas pelos índios as por eles habitadas em caráter permanente, as utilizadas para suas atividades produtivas, as imprescindíveis à preservação dos recursos ambientais necessários a seu bem-estar e as necessárias a sua reprodução física e cultural, segundo seus usos, costumes e tradições". Esta definição não tem a ver, que se faça bem entendido, com terras ocupadas, ininterruptamente ou não, desde tempos pré-coloniais até os dias de hoje, mas à maneira tradicional como grupos indígenas se relacionam em tempos recentes com seus territórios (ver Silva et al. 1994; Santos \& Pacheco de Oliveira 2003; Leite 2005; Eremites de Oliveira 2007, 2012).

\section{REFERÊNCIAS}

Almeida, M. A. D. de. 2015. Diálogos entre antropologia e direito à luz dos laudos periciais, in Laudos antropológicos em perspectiva. Organizado por J. Pacheco de Oliveira et. al., pp.23-47. Brasília: ABA. 
Atalay, S. 2006. Indigenous Archaeology as decolonizing practice. The American Indian Quarterly 30(3-4): 280-310.

Balandier, G. 1993. A noção de situação colonial. Trad. de N. N. Campanário. Revisão de Paula Monteiro. Cadernos de Campo 3: 107-131.

Barreto, C. 1999-2000. A construção de um passado pré-colonial: uma breve história da Arqueologia no Brasil. Revista USP 44: 32-51.

Bezerra, M. 2011. As Moedas dos Índios: um estudo de caso sobre os significados do patrimônio arqueológico para os moradores da Vila de Joanes, Marajó, Brasil. Boletim do Museu Paraense Emilio Goeldi - Ciências Humanas 6: 57-70.

Brand, A. J. 1997. O impacto da perda da terra sobre a tradição Kaiowá/Guarani: os difíceis caminhos da palavra. Tese de Doutorado. Programa de Pós-Graduação em História, Pontifícia Universidade Católica do Rio Grande do Sul, Porto Alegre/RS.

Cabral, J. de P. 2004. Uma história de sucesso: a Antropologia Brasileira vista de longe, in O campo da Antropologia no Brasil. Organizado por W. Trajano Filho \& G. L. Ribeiro, pp.249-265. Rio de Janeiro: Contra Capa/ABA.

Caldarelli, S. B. (org.). 1997. Atas do Simpósio sobre Política Nacional do Meio Ambiente e Patrimônio Cultural. Goiânia: IGPA-UCG/ Fórum Interdisciplinar para o Avanço da Arqueologia.

Caldarelli, S. B. \& M. do C. M. M. dos Santos. 2000. Arqueologia de Contrato no Brasil. Revista USP 44: 52-73.

Cardoso de Oliveira, R. 1978. A Sociologia do Brasil indigena. Brasília: Editora UNB.

Cardoso de Oliveira, R. 2002. Os diários e suas margens: viagem aos territórios Terêna e Tükúna. Brasília: Editora UnB.
Cavalcante, T. L. V. 2013. Colonialismo, território e territorialidade: a luta pela terra dos Guarani e Kaiowa em Mato Grosso do Sul. Tese de Doutorado. Programa de PósGraduação em História, Universidade Estadual Paulista "Júlio de Mesquita Filho", Assis/SP.

Chesnais, F. 1996. A Mundialização do Capital. Trad. de S. F. Foá. São Paulo: Xamã.

Cooper, F. 2005. Colonialism in Question: Theory, Knowledge, History. Berkeley: University of California Press.

Dias, A. S. 1995. Um projeto para a Arqueologia Brasileira: breve histórico da implementação do Programa Nacional de Pesquisas Arqueológicas (PRONAPA). Revista do CEPA 19(22): 25-39.

Dirks, N. B. (ed.). 1995. Colonialism and Culture. Ann Arbor: The University of Michigan Press.

Eremites de Oliveira, J. 2002. A Arqueologia Brasileira da década de 1980 ao início do século XXI: uma avaliação histórica e historiográfica. Estudos IberoAmericanos 28(2): 25-52.

2007. Cultura material e identidade étnica na arqueologia brasileira: um estudo por ocasião da discussão sobre a tradicionalidade da ocupação Kaiowá da Terra Indígena Sucuri'y. Cultura e sociedade 10(1): 95-113.

2010. Sobre a necessidade do trabalho antropológico para o licenciamento ambiental: avaliação dos impactos gerados a partir da pavimentação asfáltica da Rodovia BR-384 sobre a comunidade Kaiowa de Nande Ru Marangatu. Revista Eletrônica História em Reflexão 4: 1-24.

.2012a. A história indígena no Brasil e em Mato Grosso do Sul. Espaço Ameríndio 6(2): 178-218.

.2012b. O uso da arqueologia para a produção de laudos antropológicos sobre 
terras indígenas em Mato Grosso do Sul, Brasil. Tellus 12(22): 27-48.

2014. Jus Sperniandi: proposta de criação de uma graduação em Antropologia em Mato Grosso do Sul, Brasil. Cadernos do LEPAARQ 9(21): 1-37.

2015. (Re) aproximando os campos da Antropologia Social e da Arqueologia no Brasil: Etnoarqueologia em laudos antropológicos judiciais sobre terras indígenas em Mato Grosso do Sul, in Laudos antropológicos em perspectiva. Organizado por J. Pacheco de Oliveira et al., pp.234-261. Brasília:ABA.

Eremites de Oliveira, J. \& L. M. Pereira. 2009a. Ñande Ru Marangatu: laudo antropológico e bistórico de uma terra Kaiowa na fronteira do Brasil como Paraguai, município de Antônio João, Mato Grosso do Sul. Dourados: Editora UFGD.

2009b. Relatório antropológico complementar dos impactos socioambientais do Projeto São Francisco, atual Serra da Borda Mineraşão e Metalurgia, sobre os Katitaurlu das terras indígenas Sararé e Paukalirajausu, em Mato Grosso. Relatório. Dourados: s/ed. Inédito.

2011. Estudos antropológicos de complementação dos impactos socioambientais gerados pelo empreendimento Linha de Transmissão em 230 KV Chapadão do Sul (SE Chapadão) Campo Grande (SE Imbirussu) Sidrolandia (SE Sidrolândia) Anastácio (SE Anastácio) sobre os Terena das Terras Indigenas Buriti e Tereré ou Buritizinho, no estado de Mato Grosso do Sul. Relatório. Dourados: s/ed. Inédito.

2012. Terra Indigena Buriti: perícia antropológica, arqueológica e bistórica sobre uma terra terena na Serra de Maracaju, Mato Grosso do Sul. Dourados: Editora UFGD.

Eremites de Oliveira, J. et al. 2011a. Estudos antropológicos e ambientais complementares sobre os impactos socioambientais gerados pelas obras de ampliação da capacidade e reordenamento do tráfego da rodovia estadual MS 156, trecho Dourados-
-Itaporã, Lote II, Km 7,800, sobre os Guarani, Kaiowa e Terena das Terras Indígenas Dourados e Panambizinho, município de Dourados, Mato Grosso do Sul. Relatório. Dourados: s/ed. Inédito.

2011b. Laudo antropológico referente à diligência técnica realizada em parte da área da antiga Fazenda Bananal, mais conhecida como Santuário dos Pajés, localizada na cidade de Brasília, Distrito Federal, Brasil. Relatório. Dourados-Brasília: s/ed. Inédito.

Fabian, J. 2013. O tempo e o outro: como a Antropologia estabelece seu objeto. Tradução de Denise J. Duarte. Petrópolis: Vozes.

Ferreira, L. F. 2013. Essas coisas não lhes pertencem: relações entre legislação arqueológica, cultura material e comunidades. Revista de Arqueologia Pública 7: 87-106.

Funari, P. P. A. 1989. Brazilian Archaeology and World Archaeology: some remarks. Word Archaeological Bulletin 3: 60-68.

1994. Arqueologia Brasileira: visão geral e reavaliação. Revista de História da Arte e Arqueologia, Campinas, 1: 23-41.

Gnecco, C. 2009. Caminos de la Arqueología: de la violencia epistémica a la relacionalidad. Boletim do Museu Paraense Emílio Goeldi-Ciências Humanas 4(1): 15-26.

Gnecco, C. \& C. H. Langebaek (ed.). 2006. Contra la tiranía tipológica en Arqueología: una visión desde Sudamérica. Bogotá: Uniandes.

González Casanova, P. 1963. Sociedad plural, colonialismo interno y desarrollo en América Latina. Revista del Centro Latinoamericano de Ciencias Sociales 6(3): 15-32.

. 1995. O colonialismo global e a democracia. Rio de Janeiro: Civilização Brasileira.

2002. O colonialismo interno, in Exploração, colonialismo e luta pela democracia na América Latina, pp. 82-109. Petrópolis: Vozes; Rio de Janeiro: LPP; Buenos Aires: Clacso. 
2006. Colonialismo interno [una redefinición], in La teoria marxista hoy: problemas y perspectivas. Compilado por A.A. Boron, pp. 409-434. Buenos Aires: Clacso.

Himes, D. H. (ed.). 1972. Reinventing Anthropology. Ann Arbor: The University of Michigan Press.

Lander, E. (org.). 2005. A colonialidade do saber: eurocentrismo e ciências sociais. Perspectivas latino-americanas. Buenos Aires: CLACSO.

Leite, I. B. (org.). 2005. Laudos periciais antropológicos em debate. Florianópolis: NUER/ ABA.

Martins, G. R. 2004. Parecer sobre o laudo pericial na área de Arqueologia, relativo a proposta de ampliação da Reserva Indígena Buriti, em MS. In: Processo $n^{\circ}$. 2001.60.00.003866-3 - $3^{a}$ Vara da $1^{a}$ Subseção Judiciária de Mato Grosso do Sul. Campo Grande, Justiça Federal, p.3752-3767. Inédito.

Mignolo, W. D. 2008. Desobediência epistêmica: a opção descolonial e o significado de identidade em política. Tradução de Ângela Lopes Norte. Cadernos de Letras da UFF 34: 287-324.

Moraes, I. P. de M. 2012. Do tempo dos Pretos d'antes aos Povos do Aproaga: patrimônio arqueológico e territorialidade quilombola no vale do rio Capim (PA). Dissertação de Mestrado. Programa de Pós-Graduação em Antropologia, Universidade Federal do Pará, Belém/ PA.

Moro Abadía, O. 2006. The history of Archaeology as a "colonial discourse". Bulletin of the History of Archaeology 16(2): 4-17.

Pacheco de Oliveira, J. 2006. Entre la ética del diálogo intercultural y una nueva modalidad de colonialismo. Los pueblos indígenas en las Directrices del Banco Mundial, in Hacia una Antropología del Indigenismo, pp.201-218. Compilado por J. Pacheco de Oliveira. Rio de Janeiro:
Contra Capa; Lima: Centro Amazónico de Antropología y Aplicación Práctica.

Peirano, M. G. S. 2000. A Antropologia como ciência social no Brasil. Etnográfica 4(2): 219-232.

O’Dwyer, E. C. 2015. Antropologias praticadas em contextos de nation-building e questões de ética na pesquisa, in Laudos antropológicos em perspectiva, pp.169-178. Organizado por J. Pacheco de Oliveira et al. Brasília: ABA.

Pels, P. 1997. The Anthropology of colonialism: culture, history, and the emergence of Western Governmentality. Annual Reviews of Anthropology 26:163-183.

. 2008. What has anthropology learned from the anthropology of colonialism? Social Anthropology 16(3): 280290.

Prous, A. 1992. Arqueologia Brasileira. Brasília: Editora UnB.

Roberto de Paula, L. 2010. Antropologia, desenvolvimento e estudos de impacto ambiental: a responsabilidade social do antropólogo revisitada.R@U - Revista dos Alunos do PPGAS-UFSCar 2(2): 252-281.

Rocha, B. C. da et al. 2013. Arqueologia pelas gentes: um manifesto. Constatações e posicionamentos críticos sobre a arqueologia brasileira em tempos de PAC. Revista de Arqueologia 26(1): 130-140.

Trigger, B. G. 2004. História do Pensamento Arqueológico. Tradução de Ordep T. Serra. São Paulo: Odysseus.

$\mathrm{SAB}$ - Sociedade de Arqueologia Brasileira. 2002. Anais do Simpósio A Arqueologia no Meio Empresarial - 2000. Goiânia: SAB/ UCG-IGPA.

Santos, A. F. M. \& J. Pacheco de Oliveira. 2003. Reconhecimento étnico em exame: dois estudos sobre os Caxixó. Rio de Janeiro: Contra Capa. 
Silva, F. A. et al. 2008. Arqueologia, Etnoarqueologia e História Indígena um estudo sobre a trajetória histórica da ocupação indígena em territórios do Mato Grosso e do Mato Grosso do Sul: a Terra Indígena Kaiabi e a Aldeia Lalima. Revista do Museu de Arqueologia e Etnologia 17: 509514.

Silva, F. A. et. al. 2011. Arqueologia colaborativa na Amazônia: Terra Indígena Kuatinemu, Rio Xingu, Pará. Amazônica 3(1): 32-59.

Silva, O. S. et al. 1994. A perícia antropológica em processos judiciais. Florianópolis: Edufsc.

Smith, L. T. 2005. Descolonizing methodologies: research and indigenouspeoples. $8^{\mathrm{a}} \mathrm{imp}$. London, Zed Books Ltd; Dunedin: University of Otago Press.

Souza, A. M. de. 1991. História da Arqueologia Brasileira. Pesquisas (Série Antropologia) 46:1-157.

Stuchi, F. F. 2010. A ocupação da Terra Indigena Kaiabi: Etnoarqueolgia e História Indígena. Dissertação de Mestrado em Arqueologia, Universidade de São Paulo, São Paulo/SP.

Wanderley, E. C. G. 2013. "É pote de parente antigo!" A relação dos indígenas Apurina da Terra Indigena Caititu com os sitios e objetos arqueológicos, Lábrea/AM. Dissertação de Mestrado. Programa de Pós-Graduação em Antropologia, Universidade Federal do Pará, Belém/PA.

Wichers, C. A. de M. 2010. Museus e Antropofagia do Patrimônio Arqueológico: caminhos da prática brasileira. Tese de Doutorado em Museologia, Universidade Lusófona de Humanidades e Tecnologia, Lisboa, Portugal.

Zanettini, P. E. 2009. Projetar o futuro para a Arqueologia Brasileira: um desafio de todos. Revista de Arqueologia Americana 27: 71-87.
Zhouri, A. \& R. Oliveira. 2007. Desenvolvimento, conflitos sociais e violência no Brasil rural: o caso das usinas hidrelétricas. Ambiente \& Sociedade 10(2): 119-135.

Recebido em 18/07/2015

Aprovado em 01/09/2015 